\title{
Hospital Based Nutrition Rehabilitation of Severely Undernourished Children Using Energy Dense Local Foods
}

\author{
RaJa Sriswan Mamidi, Bharati KulKarni, KV Radhakrishna ANd Veena Shatrugna \\ From the Clinical Division, National Institute of Nutrition, Hyderabad, India. \\ Correspondence to: Dr Bharati Kulkarni, Scientist C, National Institute of Nutrition (Indian Council of Medical Research), \\ Jamai Osmania PO, Hyderabad 500 007, India. bharati70@yahoo.com
}

\begin{abstract}
Objective: To examine the catch up growth in severely wasted children using energy dense local foods at a hospital based nutrition rehabilitation unit.

Design: Retrospective cohort.

Setting: In-patient ward at a tertiary care government pediatric hospital in Hyderabad.

Patients: Children with severe malnutrition ( $n=309)$ admitted to nutrition ward from January 2001 to December 2005.

Intervention: A diet based on energy dense local foods along with multivitamin-multimineral supplements.
\end{abstract}

Main outcome measures: Catch up growth ( $\mathrm{g} / \mathrm{kg} / \mathrm{day})$ during each week of hospital stay.
Results: Mean age of the children was 25 months (range 2-60). Their baseline weight for height (WHZ) Z score was -4.1 . Mean weight gain was moderate $(5 \mathrm{~g} / \mathrm{kg} /$ day) and baseline $\mathrm{WHZ}$ score had a significant negative relationship to the weight gain. The prevalence of morbidities was high and the commonest morbidity was fever. Weight gain was higher by almost $40 \%$ in the absence of morbidities in any week.

Conclusions: The diet based on local energy dense foods was found to be suitable for the nutrition rehabilitation of severely malnourished children though the rate of weight gain was moderate.

Key words: Catch up growth, Children, India, In-patient, Nutrition rehabilitation, Protein energy malnutrition.

Published online 2010, March 15. PII: S097475590900379-1

$\mathrm{M}$ anagement of severely malnourished children consists of an initial stabilization phase followed by a longer rehabilitation phase, as per WHO guidelines(1). During rehabilitation, rapid catch up growth in weight ( $>10 \mathrm{~g} / \mathrm{kg} /$ day) needs to be attained as it facilitates early discharge and prevents secondary infections.

It is hard to find studies regarding catch up growth during rehabilitation from hospitals in India due to centrality of curative medical care, which takes most of the time of the doctors. In addition, there is also heavy workload on the hospital staff and standardized weighing scales are not available in many hospitals. As a result, infrastructure for documentation of catch up growth in nutrition rehabilitation with various diets (due to diverse food habits across the country) is lacking.

We therefore examined the catch up growth in children suffering from severe malnutrition using energy dense local foods.

\section{METHODS}

The study was carried out at Niloufer Hospital, Hyderabad where National Institute of Nutrition manages a nutrition ward to provide nutrition support to the children who suffer from severe malnutrition. Severely undernourished children who get admitted to the hospital for various reasons are referred to the nutrition ward by the clinicians attending to these patients after the initial treatment. This includes necessary investigations, treatment of 
infections, correction of electrolyte imbalance, and administration of broad-spectrum antibiotics and this is carried out at other wards. The usual practice is to provide potassium chloride if the child has symptoms suggestive of hypokalemia. This initial phase of treatment usually requires a week and thereafter a child is transferred to the nutrition ward for nutrition rehabilitation.

Criteria for admission to the nutrition ward is presence of severe wasting (weight for height $\mathrm{Z}$ [WHZ]score <-3) or nutritional edema or risk of severe wasting due to faulty feeding practices(2). Once transferred to the ward, the child is examined and necessary investigations including Mantoux test, hemoglobin estimation, chest $X$-ray etc are carried out. Routine massive vitamin A administration is done and iron is withheld for the first week as per the WHO guidelines(1). Nursing staff is available round the clock for supervised feeding. Broad spectrum antibiotics are administered to the children who have not received antibiotics in other wards.

The diet provided to the children follows the WHO recommendations regarding calories and proteins. However, it is modified to include the local foods so that it is possible for families to maintain it at home. This diet has been derived based on previous studies by National Institute of Nutrition at this centre(3). The child is initially put on a maintenance diet of about $100 \mathrm{kcal} / \mathrm{kg} /$ day, which is slowly increased up to $170-220 \mathrm{kcal} / \mathrm{kg} /$ day. A typical diet of a child weighing $7 \mathrm{~kg}$ consists of $350 \mathrm{ml}$ of milk (fortified with oil to increase the energy density), 250g of khichdi (rice and dhal in 2:1 ratio with added oil), 1-2 slices of bread, 2 eggs and a banana, which provides around 170 to $200 \mathrm{kcal} / \mathrm{kg} /$ day and 3 to 4 grams of protein $/ \mathrm{kg} /$ day. Micronutrients are provided in the form of multivitamin-multimineral syrups containing zinc sulphate, nicotinamide, thiamine hydrochloride, riboflavin, pyridoxine, copper sulphate, potassium iodide, selenium, cyanocobalamin, Vitamin A, cholecalciferol and calcium. Folic acid is given regularly but iron is withheld during the initial phase of rehabilitation. Iron supplementation is started once the child starts gaining weight. Children are fed every 2 hours initially and once appetite improves, they are fed ad libitum. Foods consumed by the children were recorded in a sub sample of 80 children who participated in another study(4).

All the children are weighed each morning on an electronic weighing scale (SECA, Hamburg, Germany) to the nearest gram. Length is measured in children $\leq 2$ years on day 1 to the nearest $0.1 \mathrm{~cm}$ with an infantometer made in-house at our institute. For children aged $>2$ years, height is measured with an anthropometric rod (SECA, UK). The doctor clinically examines the child every morning and appropriate treatment is given. Any complaints narrated by the caretaker and corroborated by the nurses are noted in the case sheet. Temperature is recorded 8 hourly and charts are maintained.

For the present study, case sheets were obtained from January 2001 to December 2005. Only those case sheets were selected where the child stayed for $\geq 7$ days at the nutrition ward and the child was less than 5 years of age. The following details were obtained from the case sheets - age, sex, hemoglobin, initial clinical diagnosis indicating the cause of admission to the hospital and presence or absence of edema, days of stay at other ward and at nutrition ward, height on day 1 , weight on day 1 , day 7 , day 14 , day 21, day 28, day 35, and day of discharge. Day 1 represents the first day at nutrition ward and week 1 represents the first week at nutrition ward. Weight gain in each week was calculated in $\mathrm{g} / \mathrm{kg} /$ day based on WHO guidelines(1).

Rate of weight gain was also calculated for the entire period of hospital stay (rate of weight gain for the entire duration of the hospital stay).

Weight for height Z (WHZ) score, weight for age Z (WAZ) score and height for age Z (HAZ) score were calculated at the beginning of each week using WHO anthro (v2.0.4) software. Height was assumed to be the same in all the weeks, as catch up growth in height in the first few weeks of rehabilitation is usually not seen.

Morbidities were calculated for individual weeks. Days of fever in that week were noted from temperature charts (presence of at least one spike of temperature $\geq 99$ degree Fahrenheit on a given day was considered as a day of fever). Days of diarrhea in 
that week were noted when doctor's notes mentioned diarrhea on that day. Days of other morbidities such as cough, vomiting and respiratory distress etc were noted similarly. Total morbidity score was calculated by adding up all the morbidity days in that week. For example, if a child had fever and diarrhea on the same day, morbidity score was calculated by adding up the two morbidities to give a score of 2 for that day. If a child had fever for 3 days in a week without any other morbidity, morbidity score was calculated as 3 for that week. If a child had only fever for one day and fever with vomiting on another day in the same week, morbidity score is calculated as 3 for that week.

\section{Statistical analysis}

All analyses were performed with the statistical package for social science (SPSS) statistical software for windows, 11 (SPSS Inc. USA). Mean and SD were calculated for continuous variables and frequencies were calculated for categorical variables. One-way ANOVA with Scheffe's post-hoc tests for more than two groups and student's t test for two groups were calculated to see significant differences. Simple regression analyses were used to assess the association of baseline WHZ score with the rate of weight gain for the entire duration of the hospital stay. Significance was tested at $<0.05$ level.

\section{RESUlts}

Children admitted for nutrition rehabilitation belonged to the lowest socioeconomic strata of the society. A total of 309 consecutive records were available for analysis. Out of these, 15 children were readmitted to the ward. However, this number is likely to be an underestimate of the true relapse rate, as children may not get admitted to the same hospital or may not have been referred to the nutrition ward from other wards.

Information on few variables was missing in the records in some cases and available numbers are mentioned in parentheses in tables. Mean age of the

TABLE I Weight Gain (g/kg/day) in MALnOURISHEd CHILdREN

\begin{tabular}{lll}
\hline & Edema present $(n=56)$ & Edema absent $(n=253)$ \\
\hline Age (mo) & $32 \pm 13$ & $24 \pm 15^{* *}$ \\
Male:Female & $29: 27$ & $134: 119$ \\
Duration of stay in nutrition ward (d) & $28 \pm 20(56)$ & $26 \pm 20(253)$ \\
Hemoglobin g/dL & $8.3 \pm 2.3(48)$ & $9.4 \pm 2.3^{*}(194)$ \\
Cause of admission \% & & \\
$\quad$ Diarrhea & $23(13)$ & $26(67)$ \\
$\quad$ Pneumonia & $5(3)$ & $12(31)$ \\
$\quad$ Others & $27(15)$ & $21(53)$ \\
$\quad$ Tuberculosis & $20(11)$ & $12(31)$ \\
$\quad$ Undernutrition & $25(14)$ & $28(71)$ \\
Baseline WHZ score & $-4.3 \pm 1.2(53)$ & $-4.0 \pm 1.3(243)$ \\
Baseline HAZ score & $-4.2 \pm 1.6(54)$ & $-3.7 \pm 1.9(246)$ \\
Baseline WAZ score & $-5.0 \pm 1.1(56)$ & $-4.8 \pm 1.3(253)$ \\
Rate of weight gain (g/kg/day) & & \\
$\quad$ week 1 & & $5.8 \pm 7.0(252)$ \\
$\quad$ week 2 & $7.0 \pm 9.4(43)$ & $5.7 \pm 7.7(169)$ \\
$\quad$ week 3 & $4.1 \pm 5.7(31)$ & $5.5 \pm 6.6(123)$ \\
week 4 & $4.8 \pm 5.8(22)$ & $5.2 \pm 5.7(87)$ \\
week 5 & $5.2 \pm 7.8(14)$ & $3.7 \pm 6.8(64)$
\end{tabular}

All the values are Mean $\pm S D ;{ }^{*} P<0.01 ;{ }^{* *} P<0.001$; WHZ-weight for height $Z$ score; HAZ- height for age $Z$ score; WAZ -weight for age $Z$ score. 
children was 25 months (range 2-60 months). Baseline HAZ, WAZ and WHZ scores were -3.8 (range -11.1 to 1.1 ), -4.8 (range -8.1 to 1.0 ), and -4.1 (range -8.1 to -1.2), respectively. Among them, 53\% were boys, $18 \%$ had edema and $20 \%$ had severe anemia (hemoglobin $<7 \mathrm{~g} / \mathrm{dL}$ ). The calorie and protein intakes calculated in a sub sample during nutrition rehabilitation were (mean \pm SD) $178 \pm 54$ $\mathrm{kcal} / \mathrm{kg} /$ day and $4.1 \pm 1.9 \mathrm{~g} / \mathrm{kg} /$ day, respectively.

Table I depicts the general characteristics and rate of weight gain $(\mathrm{g} / \mathrm{kg} / \mathrm{day})$ in children with and without edema. Overall, the mean rate of weight gain calculated for the total duration of the hospital stay in the entire sample was $5 \mathrm{~g} / \mathrm{kg} /$ day. Eight percent of the children did not gain weight, $44 \%$ of the children had poor catch up growth $(<5 \mathrm{~g} / \mathrm{kg} / \mathrm{day}), 35 \%$ of the children had moderate catch up growth $(5-10 \mathrm{~g} / \mathrm{kg} /$ day) and $12 \%$ had rapid catch-up growth $(>10 \mathrm{~g} / \mathrm{kd} /$ day). Mean rate of weight gain in each week appeared to decrease with increasing age (Table II), but the difference was not statistically significant.

Most of the children had 1-2 days of fever during admission and about $10-12 \%$ children had diarrhea. Longer duration of fever worsened the rate of weight gain in each week. Similarly, higher morbidity score was associated with lower rate of weight gain.

In simple linear regression analysis with rate of weight gain for the total duration of the hospital stay as dependent variable and baseline WHZ score on day 1 as an independent variable, baseline WHZ score was significant determinant $(P<0.001)$ of weight gain explaining $12 \%$ of the variation in total weight gain (Fig. 1).

\section{Discussion}

The study provides a database on catch up growth in weight during nutrition rehabilitation of severely undernourished children when treated with energy dense local foods. The mean rate of weight gain at our center was $5 \mathrm{~g} / \mathrm{kg} /$ day (Table 1). Despite staying in the ward for 5 weeks, mean WHZ scores of $40 \%$ of children were $<-3$ due to severity of baseline wasting and moderate rates of catch up growth. Rapid catch up growth of $>10 \mathrm{~g} / \mathrm{kg} /$ day in hospital-based rehabilitation was seen in centers from Jamaica and Bangladesh(5-7). Studies reporting catch up growth during hospital based nutrition rehabilitation in India are not available for comparison.

WHO recommends caloric intake of 170-220 $\mathrm{kcal} / \mathrm{kg} /$ day for rapid catch up growth during nutrition rehabilitation. The mean calorie and protein intakes at the ward calculated in a sub sample of children were about $180 \mathrm{kcal} / \mathrm{kg} /$ day and $4 \mathrm{~g} / \mathrm{kg} /$ day, respectively, which may be considered adequate. Zinc was found to be a limiting factor despite high calorie diets in a study from Bangladesh(8). However, zinc and other micronutrients are routinely supplemented at our center. Milk based diets were found to be superior to plant based diets for catch up growth $(9,10)$ and regenerating serum albumin(11,12). The diet at our center can be considered as a mixed diet with average milk intakes of about $350 \mathrm{~mL}$ per day (range $50 \mathrm{~mL}$ to $850 \mathrm{~mL}$ ). Rapid catch growth was possible with local staples consisting of meat, fish, vegetables and palm oil in a study from Nigeria(13). With the advent of ready to use therapeutic food (RUTF), much more rapid catch up growth ( $\cong 15 \mathrm{~g} / \mathrm{kg} / \mathrm{day}$ ) was observed as compared to the WHO recommended milk based diet (F-100) in a therapeutic feeding center in Senegal(14).

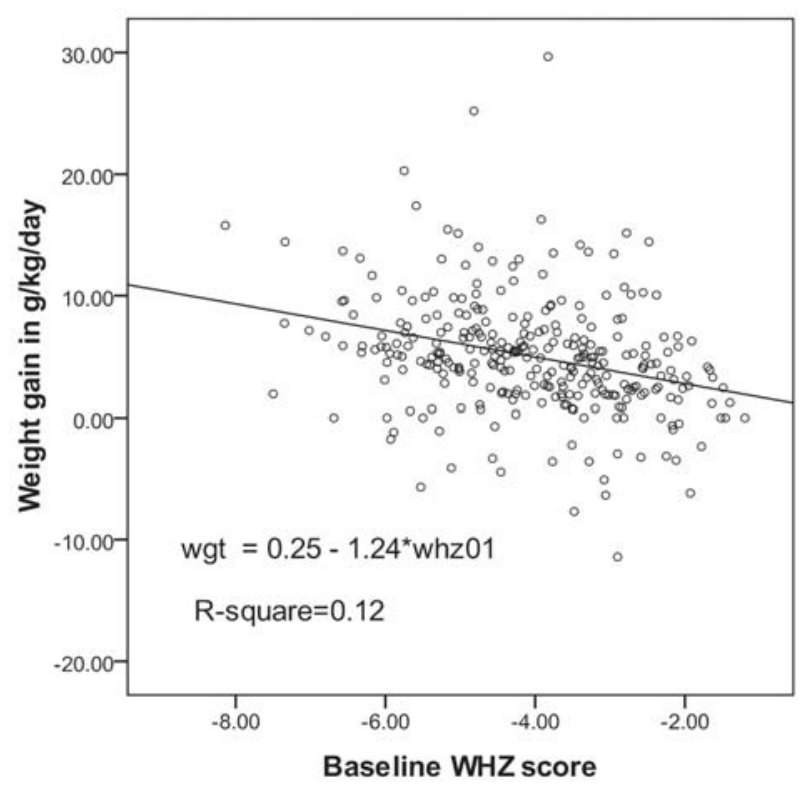

FIG. 1 Linear regression plot with (weight for height Z) WHZ score as independent variable and total weight gain (wgt) as dependent variable in children without edema. 
TABLE II Weight Gain (g/kg/d) in Each Week in Relation to Baseline

\begin{tabular}{|c|c|c|c|c|c|c|}
\hline \multicolumn{7}{|c|}{ Rate of weight gain } \\
\hline & Week 1 & Week 2 & Week 3 & Week 4 & Week 5 & Total \\
\hline \multicolumn{7}{|l|}{ Age } \\
\hline$\leq 12$ months & $6.2 \pm 8.9^{1}(80)$ & $4.9 \pm 9.1(53)$ & $7.2 \pm 6.9(41)$ & $7.0 \pm 6.1(32)$ & $4.4 \pm 8.5(23)$ & $5.3 \pm 5.6(80)$ \\
\hline 13-24 months & $6.5 \pm 6.9(80)$ & $7.9 \pm 7.4(51)$ & $4.9 \pm 6.2(36)$ & $2.9 \pm 5.4(24)$ & $2.8 \pm 5.7(21)$ & $6.1 \pm 5.2(80)$ \\
\hline 25-36 months & $5.6 \pm 5.5(56)$ & $4.9 \pm 6.8(38)$ & $4.7 \pm 7.2(31)$ & $6.8 \pm 5.1(18)$ & $1.7 \pm 7.1(9)$ & $4.8 \pm 4.1(56)$ \\
\hline 37-48 months & $3.8 \pm 3.6(19)$ & $5.4 \pm 6.1(12)$ & $5.1 \pm 5.4(6)$ & $1.8 \pm 5.1(5)$ & $8.8 \pm 4.7(4)$ & $3.7 \pm 3.1(19)$ \\
\hline 49-60 months & $4.3 \pm 4.0(18)$ & $2.8 \pm 5.5(15)$ & $3.6 \pm 3.3(9)$ & $3.4 \pm 4.0(8)$ & $3.5 \pm 3.0(7)$ & $3.4 \pm 2.5(18)$ \\
\hline \multicolumn{7}{|c|}{ Baseline WHZ score } \\
\hline$\leq-3$ & $6.6 \pm 7.2(183) * *$ & $* 6.9 \pm 7.7(110) *$ & $6.0 \pm 6.2(70)$ & $5.5 \pm 5.9(44)$ & $5.0 \pm 6.9(25)$ & $5.9 \pm 4.7(183)^{* *}$ \\
\hline$>-3$ & $3.3 \pm 5.5(59)$ & $3.9 \pm 6.8(51)$ & $4.8 \pm 6.9(50)$ & $4.8 \pm 5.6(42)$ & $2.6 \pm 6.6(37)$ & $3.1 \pm 4.4$ (59) \\
\hline \multicolumn{7}{|c|}{ Cause of admission } \\
\hline Diarrhea & $6.8 \pm 7.6(66)$ & $6.3 \pm 9.3(38)$ & $8.2 \pm 6.6(29)$ & $6.1 \pm 5.3(21)$ & $4.2 \pm 6.0(12)$ & $6.3 \pm 5.7(67)$ \\
\hline Pneumonia & $5.4 \pm 8.2(31)$ & $3.8 \pm 7.0(26)$ & $2.7 \pm 8.1(15)$ & $7.5 \pm 7.2(9)$ & $6.1 \pm 6.2(8)$ & $3.9 \pm 3.2(31)$ \\
\hline Tuberculosis & $6.4 \pm 7.8(31)$ & $8.4 \pm 7.9(27)$ & $5.4 \pm 7.4(24)$ & $2.9 \pm 6.0(21)$ & $1.8 \pm 7.1(16)$ & $5.8 \pm 5.5(31)$ \\
\hline Others & $4.6 \pm 7.1(53)$ & $5.6 \pm 7.3(31)$ & $3.9 \pm 5.0(23)$ & $5.0 \pm 4.8(17)$ & $3.3 \pm 8.3(14)$ & $4.3 \pm 4.8(53)$ \\
\hline No infection & $5.7 \pm 5.2(71)$ & $4.5 \pm 6.5(47)$ & $5.5 \pm 5.2(32)$ & $5.7 \pm 5.7(19)$ & $4.3 \pm 6.0(14)$ & $5.0 \pm 4.0(71)$ \\
\hline \multicolumn{7}{|l|}{ Morbidity } \\
\hline \multicolumn{7}{|c|}{ Days of fever without other morbidities } \\
\hline 0 & $7.1 \pm 6.6^{\mathrm{a}}(90)^{* *}$ & $7.4 \pm 6.0^{\mathrm{a}}(73)^{* *}$ & $7.0 \pm 5.3^{\mathrm{a}}(48)^{* *}$ & $7.8 \pm 5.0^{\mathrm{a}}(42)^{* *}$ & $6.6 \pm 5.1^{\mathrm{a}}(26)^{* *}$ & \\
\hline $1-2$ & $7.8 \pm 6.3^{\mathrm{a}}(87)$ & $7.0 \pm 7.0^{\mathrm{a}}(41)$ & $7.2 \pm 6.0^{\mathrm{a}}(35)$ & $5.3 \pm 5.1^{\mathrm{a}}(20)$ & $6.6 \pm 6.2^{\mathrm{a}}(16)$ & \\
\hline$>2$ & $2.3 \pm 6.6^{\mathrm{b}}(29)$ & $1.2 \pm 7.7^{\mathrm{b}}(20)$ & $2.5 \pm 6.3^{\mathrm{b}}(13)$ & $-0.4 \pm 3.4^{\mathrm{b}}(14)$ & $-0.3 \pm 5.6^{b}(11)$ & \\
\hline \multicolumn{7}{|c|}{ Days of diarrhea without other morbidities } \\
\hline 0 & $7.1 \pm 6.6(90)$ & $7.4 \pm 6.0(73)$ & $7.0 \pm 5.3(48)$ & $7.8 \pm 5.0(42)$ & $6.6 \pm 5.1(26)$ & \\
\hline $1-2$ & $4.5 \pm 5.2(10)$ & $5.8 \pm 8.9(11)$ & $3.2 \pm 5.8(9)$ & & $0(1)$ & \\
\hline$>2$ & & $-1.6 \pm 2.2(2)$ & & & & \\
\hline \multicolumn{7}{|c|}{ Total morbidity score } \\
\hline 0 & $7.1 \pm 6.6^{\mathrm{a}}(90)^{* *}$ & ${ }^{*} 7.4 \pm 6.0^{\mathrm{a}}(73)^{* *}$ & $7.0 \pm 5.3^{\mathrm{a}}(48)^{* *}$ & $7.8 \pm 5.0^{\mathrm{a}}(42)^{* *}$ & $6.6 \pm 5.1^{\mathrm{a}}(26)^{* *}$ & \\
\hline $1-2$ & $6.9 \pm 6.2^{\mathrm{a}}(110)$ & $6.4 \pm 7.8^{\mathrm{a}}(61)$ & $6.4 \pm 6.4^{\mathrm{a}}(51)$ & $5.2 \pm 4.7^{\mathrm{a}}(23)$ & $4.5 \pm 6.2^{\mathrm{a}}(23)$ & \\
\hline$>2$ & $1.2 \pm 7.4^{\mathrm{b}}(51)$ & $1.0 \pm 9.1^{\mathrm{b}}(33)$ & $0.6 \pm 7.7^{\mathrm{b}}(22)$ & $-0.5 \pm 3.8^{\mathrm{b}}(20)$ & $-2.6 \pm 6.3^{\mathrm{b}}(15)$ & \\
\hline
\end{tabular}

All the values are Mean $\pm \mathrm{SD} ; n$ in brackets. ANOVA (more than 2 groups), and student's t test (two groups) are calculated between rows for each variable in each week; ${ }^{*} \mathrm{P}<0.05,{ }^{* *} \mathrm{P}<0.001$.

Although the calorie-protein intakes of the children at our center appear to be adequate, the intakes of potassium and magnesium may be inadequate. WHO guidelines advocate supplemental potassium and magnesium for at least 2 weeks for all severely malnourished children. At our center, these supplements were provided when the child had clinical symptoms suggestive of hypokalemia. These supplements were not provided routinely at the ward because magnesium is not commonly available as an oral supplement, and the children received a variety of foods which were rich sources of potassium and magnesium. However, the intakes of potassium and magnesium in these children were less than the 


\section{What is AlReady KnOWn?}

- Information on catch up growth during nutrition rehabilitation of severely undernourished children reported from other countries is largely based on milk-based diets.

\section{What This Study Adds?}

- Moderate catch up growth can be achieved in severely undernourished children treated with energy dense local foods in a hospital setting.

WHO recommendation and this may have contributed to the low rates of weight gain. Better adherence to the WHO guidelines may help improving the rate of weight gain during nutrition rehabilitation of severely malnourished children.

The high prevalence of fever and presence of other morbidities is not entirely unexpected, as malnourished children are susceptible to infections due to poor immune status(15-17). Therefore, despite efforts to prevent infections, the morbidities such as fever were high. In this study, weight gain was $7 \mathrm{~g} / \mathrm{kg} /$ day when there was no morbidity, which was $40 \%$ higher than the average weight gain of $5 \mathrm{~g} / \mathrm{kg} /$ day.

Apart from the caloric intake, the severity of wasting is known to influence the rate of weight gain(18). Interestingly in the regression plot of our study, weight gain decelerated to zero when the child's baseline WHZ score approached the median (Fig. 1). With increasing age, there was a decrease in weight gain though statistically not significant. But such pattern is expected since growth rates are much higher in the first two years of life compared to the next three years.

Rapid catch up growth is required to hasten the rate of recovery and provide beds to other ailing children(19). In the present study, which included children who stayed for more than a week, only one out of five stayed for $\geq 5$ weeks. Their parents were daily-wage workers and were unable to stay for longer duration.

All the limitations of a retrospective study are applicable to this study but since our center is a research unit, the staff is well trained and experienced and records are well maintained. Moreover, as this study included data collected for 5 years, sample size was large and it was possible to carry out sub-group analyses.

INDIAN PEDIATRICS
Management of severely undernourished children as per the WHO guidelines aims at achieving weight gain of $>10 \mathrm{~g} / \mathrm{kg} /$ day and it needs to be examined whether a better adherence to WHO guidelines would improve the rate of weight gain.

\section{ACKNowledgments}

Dr B Sesikeran, Director, National Institute of Nutrition, Hyderabad, India for administrative support, and Ms Pramodini, Ms Rajkumari and other nurses for preserving the records.

Contributors: All the authors conceived and designed the study. RSM analyzed the data and wrote the paper. BK, KVR and VS guided data analysis and interpretation of data, and helped editing the paper. All the authors were involved in providing clinical care to the children involved in the study. All the authors approved the final manuscript. Funding: None.

Competing interests: None stated.

\section{REFERENCES}

1. World Health Organization. Guidelines for the inpatient treatment of severely malnourished children. Geneva: WHO; 2003.

2. World Health Organization. Multicentre Growth Reference Study Group: WHO Child Growth Standards: Length/height-for-age, weight-for-age, weight-for-length, weight-for-height and body mass index-for-age: Methods and development. Geneva: WHO; 2006.

3. Reddy V, Bhaskaram P. Treatment of severe protein energy malnutrition. Indian Pediatr 1982; 19: 243-248.

4. Radhakrishna KV, Kulkarni B, Balakrishna N, Hemalatha R, Chandrakala OA, Shatrugna V. Composition of weight gain during nutrition rehabilitation of severely under nourished children in a hospital based study from India. Asia Pac J Clin Nutr 2010; 19: 8-13. 
5. Khanum S, Ashworth A, Huttly SR. Controlled trial of three approaches to the treatment of severe malnutrition. Lancet 1994; 344: 1728-1732.

6. Ashworth A. Growth rates in children recovering from protein-calorie malnutrition. Br J Nutr 1969; 23: 835-845.

7. Iqbal HM, Dodd NS, Tahmeed A, Mothabbir MG, Jamil Kazi M, Baitun $\mathrm{N}$, et al. Experience in managing severe malnutrition in a government tertiary treatment facility in Bangladesh. J Health Popul Nutr 2009; 27: 72-79.

8. Simmer K, Khanum S, Carlsson L, Thompson RP. Nutritional rehabilitation in Bangladesh-the importance of zinc. Am J Clin Nutr 1988; 47: 10361040.

9. Graham GG, Baertl JM, Cordano A. Studies in infantile malnutrition. V. The effect of dietary protein source on serum proteins. Am J Clin Nutr 1966; 18: 16-19.

10. Pereira SM, Begum A. The manifestations and management of severe protein-calorie malnutrition (kwashiorkor). World Rev Nutr Diet 1974; 19: 1-50.

11. Srikantia SG, Gopalan C. Clinical trials with vegetable protein foods in kwashiorkor. Indian $\mathrm{J}$ Med Res 1960; 48: 637-644.

12. Venkatachalam PS, Srikantia SG, Geeta Mehta, Gopalan C. Treatment of Nutritional Edema
Syndrome (kwashiorkor) with vegetable protein diets. Indian J Med Res 1956; 44: 539-545.

13. Smith IF, Taiwo O, Golden MHN. Plasma somatomedin in Nigerian malnourished children fed a vegetable protein rehabilitation diet. Eur J Clin Nutr 1989; 43: 705-713.

14. Diop el HI, Dossou NI, Ndour MM, Briend A, Wade S. Comparison of the efficacy of a solid ready to use food and a liquid milk-based diet for the rehabilitation of severely malnourished children: a randomized trial. Am J Clin Nutr 2003; 78: 302307.

15. Walker SP, Grantham-McGregor SM, Powell CA, Himes JH, Simeon DT. Morbidity and the growth of stunted and nonstunted children, and the effect of supplementation. Am J Clin Nutr 1992; 56: 504-510.

16. Becker S, Black RE, Brown KH. Relative effects of diarrhea, fever and dietary energy intake on weight gain in rural Bangladeshi children. Am J Clin Nutr 1991; 53: 1499-1503.

17. Bhaskaram P. Micronutrient malnutrition, infection, and immunity: an overview. Nutr Rev 2002; 60: S40-45.

18. Ashworth A, Millward DJ. Catch-up growth in children. Nutr Rev 1986; 44: 157-163.

19. Waterlow JC. Protein-Energy Malnutrition. In: Waterlow JC, ed. London: Edward Arnold; 1992. p. 165-186. 